\title{
Brain-derived neurotrophic factor is increased in serum levels of patients with symptomatic dermographism
}

\author{
Seval Erpolat ${ }^{1}$, Huseyin Tugrul Celik², Bulent Bozkurt ${ }^{3}$ \\ ${ }^{1}$ Department of Dermatology, Faculty of Medicine, Turgut Ozal University, Ankara, Turkey \\ 2Department of Biochemistry, Faculty of Medicine, Turgut Ozal University, Ankara, Turkey \\ ${ }^{3}$ Division of Allergy, Department of Chest Medicine, Faculty of Medicine, Turgut Ozal University, Ankara, Turkey \\ Adv Dermatol Allergol 2017; XXXIV (4): 346-349 \\ DOI: https://doi.org/10.5114/ada.2017.69315
}

\begin{abstract}
Introduction: Symptomatic dermographism (SD) is the most common form of physical urticaria. However, the role of neuroimmune mechanisms in SD is unclear.

Aim: To investigate circulating levels of brain-derived neurotrophic factor (BDNF) in symptomatic dermographism. Material and methods: Thirty-two patients suffering from SD and 33 healthy subjects were included in the study. Serum BDNF levels were determined by a human enzyme-linked immunoassay (ELISA) kit. The serum C-reactive protein concentration and eosinophil counts in peripheral blood were evaluated.

Results: The BDNF serum levels were detectable in both SD patients and healthy controls. The BDNF serum levels were significantly higher in patients with SD compared with healthy controls $(p=0.004)$. There was a positive but weak correlation between serum BDNF and CRP levels; it was not statistically significant $(r=0.211, p=0.255)$. There was also a positive but weak correlation between serum BDNF and eosinophil counts; it was not statistically significant $(r=0.271, p=0.141)$.

Conclusions: The present study shows that BDNF is increased in the serum levels of patients with SD, suggesting a role for BDNF in the pathophysiology of this disorder.
\end{abstract}

Key words: symptomatic dermographism, brain-derived neurotrophic factor, neurotrophin.

\section{Introduction}

Symptomatic dermographism (also known as dermographic urticaria or urticaria factitia) (SD) is a chronic form of physical urticaria with an estimated prevalence of up to $5 \%$ of the population. It is a condition in which rubbing of the skin rapidly induces wheals, associated with pruritus and/or a burning sensation. It is the most common form of physical urticaria, affecting mainly young adults. Its mean untreated duration is 6.5 years $[1,2]$. The exact mechanism of SD remains uncertain but it is known that mast cell degranulation releases histamines and other mediators, thus causing the wheal and flare reaction $[3,4]$.

Brain-derived neurotrophic factor (BDNF) is a member of the neurotrophin family. Neurotrophins were first isolated in the central nervous system and identified as important factors for the survival and differentiation of neurons during fetal and post-natal development as well as neuronal maintenance later in life. Four members of this family have been identified and well defined: nerve growth factor (NGF), brain-derived neurotrophic factor (BDNF), neurotrophin 3 (NT-3), and neurotrophin 4/5 (NT-4/5). Neurotrophins play a critical role in the bidirectional signaling mechanisms between immune cells and the neurosensory network structures in the skin. Their effects are mediated by binding to two different receptor types: the high-affinity tyrosinekinase (TRK) receptors, and the low-affinity pan-neurotrophin receptor p75 $\left(p 75^{\mathrm{NTR}}\right.$ ), which is a member of the tumor necrosis factor superfamily. The expression of these neurotrophin receptors is widely distributed in the neurons of the peripheral and the central nervous system $[5,6]$. Neurotrophin receptor expession was also found in non-neuronal cells including epithelial cells, smooth muscle cells, and immune cells such as eosinophils and mast cells. Neurotrophins exert a variety of immunomodulatory effects on non-neuronal cells including eosinophils and mast cells which also produce neutrophins [7].

Address for correspondence: Seval Erpolat MD, Department of Dermatology, Faculty of Medicine, Turgut Ozal University, Alparslan Turkes Caddesi No: 57, 06510 Ankara, Turkey, phone: + 9031220352 50, fax: + 90312221 36 20, e-mail: Soyoral@yahoo.com Received: 11.03.2016, accepted: 1.06.2016. 
Neurotrophins have been shown to play an important role in the development and maintenance of cutaneous innervation. There is also evidence for non-neurotrophic functions of neurotrophins in the skin. These include the regulation of epidermal proliferation and apoptosis, control of hair follicle development and cycling, and melanogenesis $[5,6]$.

\section{Aim}

The role of neuroimmune mechanisms in SD is not yet clear. Thus we first investigated whether BDNF serum levels in SD are different from control subjects. Secondly, we analysed whether the relationship between serum BDNF, C-reactive protein (CRP), and eosinophil counts.

\section{Material and methods}

This study was conducted at the Turgut Ozal University Hospital (Ankara, Turkey). The study was approved by the local ethics committee. All participants gave their written informed consent. Thirty-two patients suffering from SD and 33 healthy subjects were included in the study. Inclusion criteria were: aged 18 years or older; at least a 3-month history of SD; and no history or presence of systemic or allergic diseases. Patients with SD associated with chronic idiopathic urticaria were excluded. In the same time period, age- and sex-matched non-atopic healthy subjects were recruited as controls. The diagnosis of SD was confirmed by stroking the skin of the back with a tongue blade. This procedure elicited within minutes a linear wheal and flare with itching and burning sensations.

Venous blood samples were drawn from the subjects between 08.00 and $10.00 \mathrm{~h}$ following a 12 -h fasting period, and sera were isolated and stored at $-80^{\circ} \mathrm{C}$ until analysis. Serum BDNF levels were determined by a human enzyme-linked immunoassay (ELISA) kit (catalog number EK0307, Boster Immunoleader, Boster Biological Technology, Ltd., Pleasanton, California, USA) according to the manufacturer's instructions. Serum BDNF levels were expressed as $\mathrm{pg} / \mathrm{ml}$ and the minimum detectable level of BDNF is typically $2 \mathrm{pg} / \mathrm{ml}$. The serum CRP concentration was measured by the spectrophotometric method (Roche Hitachi Cobas C501, Tokyo, Japan). An elevated serum CRP level was defined as higher than

Table 1. Demographic data and serum BDNF levels of patients with symptomatic dermographism and controls

\begin{tabular}{lcc}
\hline Variable & $\begin{array}{c}\text { Patients } \\
(n=32)\end{array}$ & $\begin{array}{c}\text { Controls } \\
(n=33)\end{array}$ \\
\hline Gender (female/male) & $22 / 10$ & $23 / 10$ \\
\hline Age & $34.7 \pm 11.03$ & $33.48 \pm 10.5$ \\
\hline Serum BDNF $[\mathrm{pg} / \mathrm{ml}]$ & $144.37 \pm 67.7$ & $112.19 \pm 79.9$ \\
\hline
\end{tabular}

$5.0 \mathrm{mg} / \mathrm{l}$. Eosinophil counts in peripheral blood were evaluated using a Coulter LH70 counter (Beckman Coulter, Brea, California, USA).

\section{Statistical analysis}

Mean \pm standard deviation (SD), median and minimum, maximum values are used to describe the quantitative variables. Also, frequency and percentages are given for the nominal data. Normality assumption was checked by Shapiro-Wilk test. The independent sample t-test and the Mann-Whitney U-test are used to compare the groups in terms of age and BDNF, respectively. The distribution of gender within study groups was analyzed by $\chi^{2}$ test. Nonparametric Spearman correlation analysis was used to analyze the relationship between BDNF and blood total eosinophil count (TEC). For all analyses the IBM-SPSS version 21.0 was used and the statistical significance was set at $p<0.05$.

\section{Results}

The mean age for the patient group was $34.7 \pm 11.03$ (22 females, 10 males), and for the control group, the mean age was $33.48 \pm 10.5$ (23 females, 10 males) (Table 1). The BDNF serum levels were detectable in both SD patients and healthy controls. The BDNF serum levels were significantly higher in patients with SD compared with healthy controls $(p=0.004)$ (Figure 1$)$. The median serum CRP concentration was $1.9 \mathrm{mg} / \mathrm{l}$. There was a positive but weak correlation between serum BDNF and CRP levels but it was not statistically significant $(r=0.211, p=$ 0.255) (Figure 2). The total eosinophil count was 147 cell/ $\mathrm{mm}^{3}$. There was a positive but weak correlation between serum BDNF and eosinophil counts but it was not statistically significant $(r=0.271, p=0.141)$ (Figure 3 ).

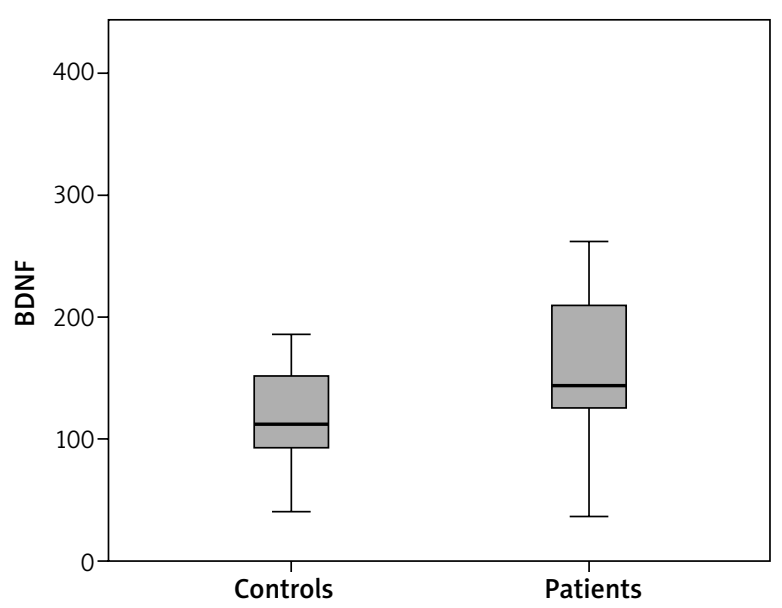

Figure 1. Distribution of brain-derived neurotrophic factor (BDNF) values in patients and controls 


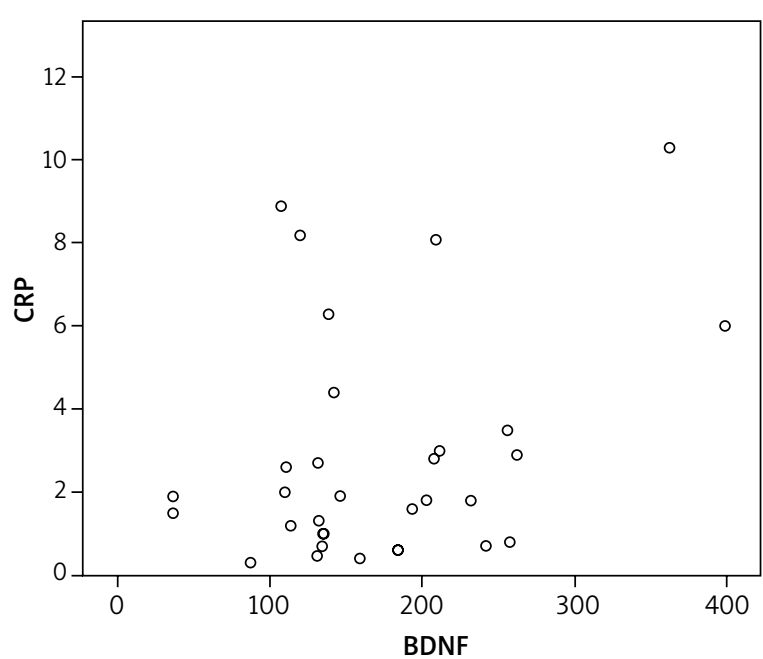

Figure 2. Correlation between serum brain-derived neurotrophic factor (BDNF) and C-reactive protein (CRP) levels in patients with symptomatic dermographism

\section{Discussion}

Symptomatic dermographism is a distressing condition. The disease is frequently idiopathic though it may have an immunological basis in some patients [1, 3, 4]. Passive transfer of the dermographic response with IgEor immunoglobulin M (IgM)-containing serum has been reported, but no allergen has been identified [8]. The pathogenesis remains unclear but trauma may release an antigen that interacts with the membrane-bound immunoglobulin E (IgE) of mast cells, thus releasing inflammatory mediators, particularly histamine, into the tissues. This process causes small blood vessels to leak, allowing fluid to accumulate in the skin $[3,4]$.

Neurotrophins exert immunomodulatory functions not only on nerves but also on immune cells $[5,6]$. Bonini et al. were the first to investigate a role of neurotrophins in patients with urticaria. They found increased levels of nerve growth factor (NGF) in urticaria patients compared with healthy controls [9]. Ozseker et al. found that NGF and BDNF levels were not increased in urticaria [10]. In another study, it was demostrated that BDNF levels of serum and skin were increased in patients with chronic spontaneous urticaria compared with non-atopic control subjects with healthy skin [11]. In this study, we found higher serum levels of BDNF in patients with SD compared with non-atopic healthy control subjects. Some studies have suggested that increased levels of NGF and BDNF and a correlation in disease activity are indicators in chronic inflammatory skin diseases including atopic dermatitis [12-14]. Thus neurotrophins seem to play a role (encompassed) in the pathogenesis of several atopic and non-atopic inflammatory skin diseases.

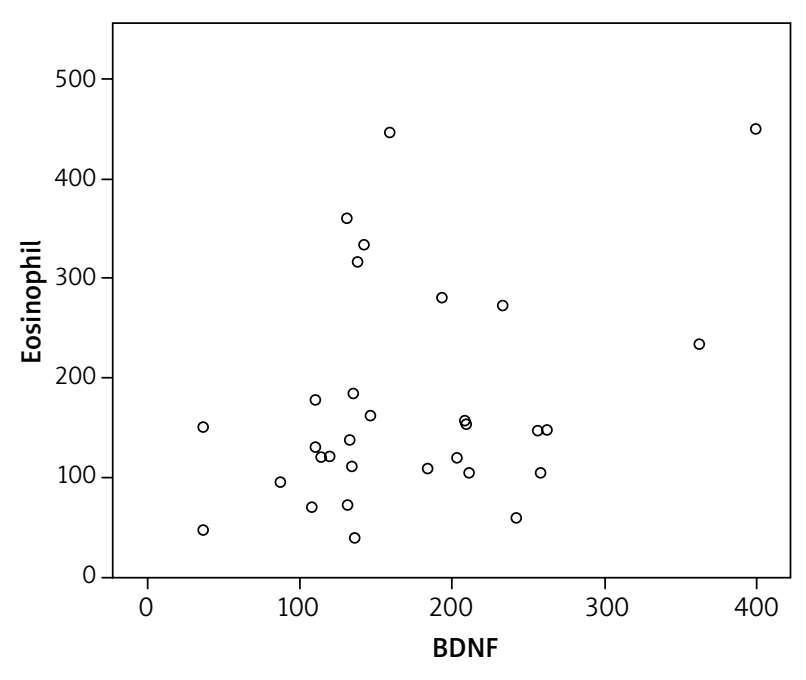

Figure 3. Correlation between serum brain-derived neurotrophic factor (BDNF) and eosinophil counts in patients with symptomatic dermographism

In the literature, there are no detailed or classified data on triggering factors and/or associated diseases in SD. Tașkapan et al. found that psychological factors and a history of stressful life events have been implicated as triggering factors in 30\% of patients [15]. Anliker et al. detected that the psychological status (accidents, fear of life, surgical intervention, chronic pain, and others) were defined in about $90 \%$ of patients with SD [16]. In another study, Schoepke et al. found that $44 \%$ of patients claimed stress to be the reason for SD [17]. Stress increases mast cell histamine release. Mast cells and their endogenous products are strongly implicated not only in the classical immune processes but also in neurophysiologic and neuropathologic events [18]. BDNF is involved as a proinflammmatory factor $[5,6]$. Schulte-Herbrüggen et al. demonstrated that BDNF can be produced by human blood monocytes and that this production is up-regulated by inflammatory mediators as tumor necrosis factor $\alpha$ (TNF- $\alpha$ ) and interleukin-6 (IL-6) [19]. Also BDNF may be released in response to stroking, rubbing and scratching of the skin of patients with SD in peripheral nerves and may serve as local stress responders that mediate neurogenic inflammation.

In this study we found a correlation between serum BDNF levels and eosinophil count to be positive but not statistically significant. Because eosinophils are a main player in allergic inflammation, neurogenic inflammation may be an important pathway triggering inflammation in the skin. These findings suggest that eosinophil is not a source of increased BDNF in the serum of SD patients and that the pathophysiology of the disease is not characterized by allergic inflammation. Skin biopsy studies should be used to evaluate the roles of eosinophil and BDNF. 
The results presented in this study demonstrate that there was a positive but weak correlation between serum BDNF levels and CRP levels but the correlation was not statistically significant. Neurotrophin's pivotal role has been described in several inflammatory conditions [9, 20]. Shin et al. showed that plasma BDNF levels correlated positively with inflammatory cytokines in hemodialysis patients, suggesting that plasma BDNF might reflect uremic inflammation in patients undergoing hemodialysis [21]. In our study, we did not observe any significant asssociations between levels of serum BDNF and CRP.

\section{Conclusions}

Our study suggests that SD is associated with alterations of serum BDNF levels. Futher studies will be needed to address the functional role of BDNF in this disorder to establish new therapeutic implications.

\section{Conflict of interest}

The authors declare no conflict of interest.

\section{References}

1. Abajian M, Schoepke N, Altrichter S, et al. Physical urticarias and cholinergic urticaria. Immunol Allergy Clin North Am 2014; 34: 73-88.

2. Breathnach SM, Allen R, Ward AM, Greaves MW. Symptomatic dermographism: natural history, clinical features, laboratory investigations and response to therapy. Clin Exp Dermatol 1983; 8: 463-76.

3. Zuberbier T. Urticaria. Allergy 2003; 58: 1224-34.

4. Black AK, Lawlor F, Greaves MW. Consensus meeting on the definition of physical urticarias and urticarial vasculitis. Clin Exp Dermatol 1996; 21: 424-6.

5. Peters EM, Raap U, Welker $P$, et al. Neurotrophins act as neuroendocrine regulators of skin homeostasis in health and disease. Horm Metab Res 2007; 39: 110-24.

6. Botchkarev VA, Yaar M, Peters EM, et al. Neurotrophins in skin biology and pathology. I Invest Dermatol 2006; 126: 1719-27.

7. Nockher WA, Renz H. Neurotrophins in allergic diseases: from neuronal growth factors to intercellular signaling molecules. J Allergy Clin Immunol 2006; 117: 583-9.

8. Murphy GM, Zollman PE, Greaves MW, Winkelmann RK. Symptomatic dermographism (factitious urticaria) - passive transfer experiments from human to monkey. Br J Dermatol 1987; 116: 801-4.

9. Bonini S, Lambiase A, Bonini S, et al. Circulating nerve growth factor levels are increased in humans with allergic diseases and asthma. Proc Natl Acad Sci USA 1996; 93: 10955-60.

10. Ozseker F, Büyüköztürk S, Gelincik A, et al. Neurotrophins: are they meaningful in chronic spontaneous urticaria? Asian Pac J Allergy Immunol 2008; 26: 83-8.

11. Rössing K, Novak N, Mommert S, et al. Brain-derived neurotrophic factor is increased in serum and skin levels of patients with chronic spontaneous urticaria. Clin Exp Allergy 2011; 41: 1392-9.
12. Namura K, Hasegawa G, Egawa M, et al. Relationship of serum brain-derived neurotrophic factor level with other markers of disease severity in patients with atopic dermatitis. Clin Immunol 2007; 122: 181-6.

13. Raap U, Werfel T, Goltz C, et al. Circulating levels of brainderived neurotrophic factor correlate with disease severity in the intrinsic type of atopic dermatitis. Allergy 2006; 61: 1416-8.

14. Toyoda M, Nakamura M, Makino T, et al. Nerve growth factor and substance $P$ are useful plasma markers of disease activity in atopic dermatitis. Br J Dermatol 2002; 147: 71-9.

15. Taşkapan O, Harmanyeri Y. Evaluation of patients with symptomatic dermographism. J Eur Acad Dermatol Venereol 2006; 20: 58-62.

16. Anliker MD, Itin P. Psychic factora as a trigger in factitial urticaria and urticaria with positive dermographism. Allergy 2001; 56: 31-2.

17. Schoepke N, Młynek A, Weller K, et al. Symptomatic dermographism: an inadequately described disease. J Eur Acad Dermatol Venereol 2015; 29: 708-12.

18. Arck PC, Slominski A, Theoharides TC, et al. Neuroimmunology of stress: skin takes center stage. J Invest Dermatol 2006; 126: 1697-704.

19. Schulte-Herbrüggen $\mathrm{O}$, Nassenstein C, Lommatzsch M, et al. Tumor necrosis factor-alpha and interleukin- 6 regulate secretion of brain-derived neurotrophic factor in human monocytes. J Neuroimmunol 2005; 160: 204-9.

20. Dicou E, Masson C, Jabbour W, Nerriere V. Increased frequency of NGF in sera of rheumatoid arthritis and systemic lupus erythematosus patients. Neuroreport 1993; 5: 321-4.

21. Shin SJ, Yoon HE, Chung S, et al. Plasma brain-derived neurotrophic factor in hemodialysis patients. Int I Med Sci 2012; 9: $772-7$. 